\title{
- The Use of Molecular Marker Methods in Plants: A Review \\ IJCRR
}

Section: General

Science

Sci. Journal

Impact Factor

4.016

ICV: $\mathbf{7 1 . 5 4}$

\author{
Thoungamba Amom ${ }^{1}$, Potshangbam Nongdam² \\ 1,2Department of Biotechnology, Manipur University, Canchipur, Imphal-795003, Manipur, India.
}

\section{ABSTRACT}

Different DNA markers have been utilized in the last few decades as important molecular tools in plants for genetic relation studies among individuals, hybrid and varietal identification, phylogenetic relationship among species, gene mapping and tracking quantitative trait loci. These markers can be broadly classified into hybridization and PCR based markers. Restriction fragment length polymorphism (RFLP) represents the hybridization based marker; while PCR dependent includes more reliable and advanced polymorphic markers like amplified fragment length polymorphism (AFLP), inter-simple sequence repeats (ISSR), single nucleotide polymorphism (SNP), sequence related amplified polymorphism (SRAP), start codon targeted (SCoT) and interprimer binding site (iPBS) among others. Functional markers (FMs) have also been developed from functionally characterised sequence motifs which are superior to random markers due to their complete linkage to trait locus alleles. With the advent of next generation sequencing (NGS) technology, excellent opportunities are offered for generating ample structural and functional genomic information in many important crops. The novel approach of genotyping-by-sequencing (GBS) employs NGS protocols for discovering and genotyping SNPs in many important crop genomes and populations. The present review focuses on the description of varied molecular markers, their methodologies, strengths and limitations as well as applications in plant breeding and genetic research.

Key Words: Polymerase chain reaction, Autoradiography, Functional markers, Genetic polymorphism, Next generation sequencing

\section{INTRODUCTION}

Knowledge of genetic structure and level of variation within and between plant populations is important for effective utilization and conservation of plants. Factors determining level and structure of genetic variation within plant species include evolutionary history characteristics, population density, mating system and mechanism of gene flow [1]. Although morphological characters, cytological and ethnological parameters have been used traditionally to characterize levels and patterns of diversity, these traits alone represent only a small portion of plant genome and are influenced by environmental factors [2]. These limit their utility in describing the potentially complex genetic structures that may exist within and between taxa [3]. Advances in biochemistry and molecular biology during the past few decades have helped to overcome these constraints by providing breeders with many powerful molecular markers [4]. Various molecular approaches for detection of genetic diversity have been devised in many plants including important horticulture crops using DNA based markers. These markersare generally independent of environmental factors and are more numerous than phenotypic characters providing clearinformation of underlying variation in the genome of an organism. The present review aims to describe different marker systems which are employed in plant identification, crop improvement, genome analysis, phylogenetic and population diversity studies.

\section{HYBRIDIZATION BASED DNA MARKER}

Restriction fragment length polymorphism (RFLP) is the only marker system representing hybridization based marker. This involves the use of restriction enzymes and hybridization of the target fragment by labelled probe. It is based on the generation of different size DNA fragments due to digestion by restriction enzymes. Genomes of individuals belonging to same species will differ in DNA fragment production after restriction digestion as a result of point mutation, insertion/deletion, translocation, inversion and duplication. RFLP steps involve the cutting of genomic DNA by restriction

\section{Corresponding Author:}

Dr. Potshangbam Nongdam, Department of Biotechnology, Manipur University, Canchipur, Imphal-795003, Manipur, India. Tel: 09774834323; Email: nongpuren@gmail.com

ISSN: 2231-2196 (Print)

Received: 27.04 .2017
ISSN: 0975-5241 (Online)

Revised: 29.05 .2017
DOI: $10.7324 / I J C R R .2017 .9171$

Accepted: 05.07 .2017 
enzyme generating different sized DNA fragments. 6 base pair cutter enzymes are most often used for RFLP analysis as they are cheaper and readily available and alsogenerate product range (200 to $20,000 \mathrm{bp}$ ) that can be conveniently separated on agarose gels [5]. The separated DNA fragments are transferred to nitrocellulose membrane by Southern blot technique [6]. Fragments of interest are identified by hybridizing with complementary radioactive labelled probe and specific banding pattern is visualized after autoradiography. The result obtained from RFLP technique depends on both restriction enzymes and number of probes. RFLP exhibits high reproducibility, codominant inheritance, easy data transferability between laboratories and provides locus specific markers. Disadvantages of the technique are time consuming, requirement of high quality and quantity of DNA, expensive radioactive probes, involvement of tedious Southern blotting method and necessity of prior sequence information for developing radio labeled probe. The RFLP markers have been employed for genetic diversity and population genetic study in varied plants like Quercus phellos [7], Saccharum spp.[8] and Vigna radiata [9].

\section{PCR BASED MARKERS}

Polymerase Chain Reaction (PCR) technique was invented by Kary Mullis in 1983 [10]. It involves the use of Taq DNA polymerase obtained from Thermus aquaticus for exponential amplification of very small amount of target DNA. The prior sequence information of flanking sites of the target DNA is required to design an appropriate primer for amplification of selected nucleotide segment. In addition to primers and DNA polymerase, supplementation of deoxynucleotide triphosphate (dNTPs) and magnesium ions along with appropriate buffer system are essential in basic PCR protocol. The PCR based markers are more advantageous over hybridization method due to less amount of DNA requirement, absence of radioisotopes, high reproducibility, more reliable and higher polymorphism in short time.

\section{Amplified fragment length polymorphism (AFLP)}

The technique employs both RFLP and PCR by ligating primer recognition sequences to the DNA fragments produced through restriction digestion [11]. Simultaneous screening of representative DNA regions distributed randomly throughout genome is the important feature of AFLP. Polymorphisms of AFLP may be produced due to mutation at restriction site, insertions, duplications or deletions inside amplification fragments and mutations of the sequences flanking the restriction sites. Good quality DNA as well as partially degraded DNA can be used for AFLP analysis but DNA should be free from restriction enzymes and PCR inhibitors. The genomic DNA might be digested by restriction enzymes which are the combination of rare cutter (Eco RI or Pstl) and frequent cutter (Msel or Taql). The double stranded oligonucleotide adaptors which do not bear initial restriction sites after ligation are developed and ligated to both ends of the fragments to give known sequence for PCR. PCR is first performed with primer combinations containing a single base pair extension while final amplification is carried out by using primer pairs with upto 3 base pair extension. AFLP fragments generated are visualized either on agarose gel or on denaturing polyacrylamide gel with autoradiography or $\mathrm{AgNO}_{3}$ staining respectively. The method is highly reproducible and its ability to determine high polymorphism in a single reaction makes AFLP one of the most sought after molecular tools for genetic analysis [12]. The limitations are the requirement of high molecular weight purified DNAs, possibility of co migrating non-homology fragments belonging to different loci.

\section{Inter simple sequence repeat (ISSR)}

This technique was first reported by Zietkiewicz at al. [13] and involved amplification of DNA segments present at an amplifiable distance between two identical microsatellite repeat regions oriented in opposite directions. Microsatellites of di, tri, tetra or penta-nucleotide core sequences are used as primers to amplify mainly inter simple sequence repeats of different sizes. ISSR primers are longer (15-35 mers) which allow higher annealing temperature resulting in higher stringency. The annealing temperature however depends on the GC content of the primer. After PCR amplification the amplified products of 200 to $2000 \mathrm{bp}$ long are separated through agarose or polyacrylamide gel electrophoresis and the resulting ISSR banding pattern can be visualized through autoradiography or $\mathrm{AgNO}_{3}$ staining. Prior sequence information of template DNA is not required for generating ISSR polymorphism. ISSR markers are simple, randomly distributed in the genome, exhibit mostly dominant inheritance pattern and require low quantity of DNA. They are employed in species and plant varietal identification, taxonomic and genetic diversity studies, gene mapping and clonal fidelity testing of in vitro derived plants[14]. The main limitations of ISSR marker are low reproducibility and homology of co-migrating amplification products [15].

\section{Single nucleotide polymorphism (SNP)}

It is the new generation molecular marker which detects polymorphisms among individuals due to changes in single nucleotide position. The simplest approach to discovering SNP in targeted region containing genes is performing direct sequencing of genomic PCR products derived from varied individuals. This approach may be costly for large scale study as there is a need for locus-specific primers and is limited to regions for which data are available. The other method based on the comparison of sequences obtained from cloned 
fragments can be considered for developing SNP map of the genome [16]. Many SNP genotyping methods are developed which combine two elements: generation of an allelic product and analysis thereof [16]. Sobrino et al. [17] assigned the majority of SNP genotyping assay to one of four groups based on molecular mechanism such as allele specific hybridization, primer extension, oligonucleotide ligation and invasive cleavage. Allele specific hybridization is based on distributing between two DNA targets differing at one nucleotide position by hybridization [18]. Two allele-specific probes are designed with polymorphic base in a central position in probe sequence. Under optimized assay conditions perfectly matched probe target is stable while one base mismatch is unstable. Most hybridization techniques are based on Dot Blot and Reverse Dot Blotmethods. Main advantages of the marker system are possibility of using small and extremely degraded DNA sample, high genomic abundance, completely automated sample processing and generation of no stutter products. The SNPs are found to be associated with plant genes of economic values e.g., presence of SNP markers for waxy gene controlling amylose content in Rice, linking of SNP with dwarfing gene in Rice and male sterility in Onion [19].

\section{Diversity arrays technology (DArT)}

This technique is based on microarray hybridization involving simultaneously genotyping of several hundred polymorphic loci spread over the genome [20]. Genomic representations are set up by genomic DNA restriction digestion followed by ligation of restriction fragments to adaptors for each of the individual DNA sample. Primers designed for adaptors and selective overhangs are used in PCR amplification in order to reduce genome complexity. DNA fragments derived from the representations are cloned and clone amplification is performed using vector-specific primersfollowed by purification and finally arrayed onto a solid support (microarray) forming a discovery array [15]. Labeled genomic representations formed from individual genomes included in the pool are hybridized to discovery array. Polymorphic clones exhibiting differential hybridization signal intensities are later set up into a "genotyping array" for routine genotyping[20].The advantages of this marker are high reproducibility, readily expandable, quick and non-requirement of prior sequence information. They are technically more demanding with long tedious steps and require skilled personnel being microarray-based technique. High investment in terms of time, physical energy, cost and advanced lab facilities limit the application of DArT markers in plant research.

\section{Conserved DNA derived polymorphism (CDDP)}

The technique was developed by Collard and Mackill [21] to fingerprint rice varieties. It was also used to evaluate the genetic diversity existed in Solanum dulcamara [22]. The short conserved sequences found in plant genome in multiple copies are targeted by primers designed to bind to these genes and generate polymorphic banding patterns. The primers also target common plant genes which are related to abiotic and biotic stress or responsible for plant development. Variation can be detected as length polymorphism within these regions since highly conserved DNA regions sharing the same priming site but differ in their genomic distribution. Single long primer amplifications with a high annealing temperature improve the reproducibility in CDDP. The DNA fragments produced are in the range of 200-1500 bp which are separated by electrophoresis and the banding patterns observed after autoradiography.

\section{Start codon targeted (SCOT)}

This is a novel marker system developed based on the short conserved regions flanking the ATG start codon in plant genome. SCoT involves the use of 18-mer primers with annealing temperature at $50^{\circ} \mathrm{C}$ [21]. Single primer is used in PCR which means the same primer is utilized as forward and reverses primer as in RAPD and ISSR markers. These markers are generally reproducible and the length and annealing temperature are not the most important factors determining reproducibility [23]. They are dominant markers which can be used for plant genetic analysis, quantitative trait loci (QTL) mapping and bulk segregate analysis [21]. The PCR products generated after amplification reaction are subjected to general agarose gel electrophoresis to separate the fragments and the bands are detected through autoradiography.

\section{Sequence related amplified polymorphism (SRAP)}

This simple, inexpensive, dominant marker technique was developed by Li and Quiros [24]. They developed the marker to specifically amplify coding regions of genome of Brassica oleraceae by targeting GC rich exons and AT rich promoters, introns and spacers. Forward primers are designed to contain GC rich sequences near the 3' end whereas reverse primers contain AT rich sequences at the 3' end. "CCGG" sequences are present in the core of forward primers while the "AATT" sequences represent the core of reverse primers [25]. The PCR amplification products are resolved following agarose gel electrophoresis and the bands are visualized through autoradiography. The DNA fragments are scored by simple absence or presence of bands as done in ISSR and RAPD markers. SRAPs have been employed to evaluate genetic variation at species level, in population genetic analysis of closely related hybrids, construction of linkage maps and in identification of quantitative trait loci [26].

\section{Inter-Primer binding site (IPBS)}

Use of retrotransposons as molecular marker has limitation due to requirement of sequence information of LTR to design 
element specific primers. There is necessity for numerous cloning and sequencing steps to obtain a few good primer sequences. Most LTR regions do not have conserved motif for direct amplification by PCR [27]. Kalender et al. [28] developed iPBS marker for identifying diverse LTR sequences and directly visualising the polymorphism among the plant cultivars. This method utilizes PBS (primer binding sites) which is a conserved sequence located adjacent to the 5'LTR and is universally present in all retrotransposons. The tRNA binds to PBS region to initiate reverse transcription by producing complementary base pairing between terminal sequence of tRNA and conserved region of PBS [29]. Primers can be designed which match the conserved region of PBS and DNA fragments of diverse LTR sequences can be generated after PCR amplification [27]. The cloning of LTR sequences was previously dependent on conserved protein coding domains limiting the screening of autonomous elements [30]. But iPBS technology allows screening of diverse LTR sequences while performing effective DNA fingerprinting. The level of polymorphism generated by iPBS amplification is as efficient as that of IRAP and RBIP markers. TheiPBS markers are highly effective and reliable for polymorphism detection and determination of clonal differentiation arising out of varied retrotransposon activities and retrotransposon recombinations [28]. iPBS is also highly reliable and powerful DNA finger printing technology which does not require the knowledge of sequence information [31]. It is used in phylogenetic and genetic diversity studies of number of plant species. Genetic diversity studies have also been successfully performed using iPBS markers in Apricot, Lens species and field pea [31, 32]

\section{FUNCTIONAL MARKERS (FMS)}

Morphological markers previously employed in plant breeding are easily affected by the environment apart from their limited number and difficulty in scoring [33]. The introduction of random DNA markers RFLP, SSR,AFLP and SNPs have brought significant improvement in plant breeding programs for producing improved crop varieties. They are used for hybridity confirmation, parents and progenies identification, evolutionary relationship study, genetic diversity determination between and within populations and mapping genes for marker assisted selection (MAS). However, the use of such markers as diagnostic tool for MAS in plant breeding has limitations because of false positives produced by genetic recombinations[34]. Genetic recombination between the marker and target locus impairs the transfer of marker information from experimental mapping population to unrelated breeding materials [35]. The random markers are derived at random from polymorphic sites in the genome and are developed independent of their relationship to any phenotypic characters. But functional markers (FMs) are de- veloped from polymorphic sites within the genes casually involved in producing phenotypic trait variation [33]. The absence of recombination for FM and its complete linkage to desired allele prevent information loss and false selection in MAB [36]. This also makes FM more effective in identification and selection of favourable alleles and enhances its diagnostic capability. Unlike random DNA markers, the phenotypic validation in MAB is not required while using FMs in plant breeding [33]. When random markers are used in $\mathrm{MAB}$, there is possibility of transferring target gene along with unwanted genes located at a distance due to linkage drag producing undesirable phenotypic traits[37].

\section{Functional marker development}

The development of functional markers requires functionally characterised genes and identification of phenotypic/ functional sites affecting plant phenotypic traits. One of the challenges of functional marker development is to relate sequence polymorphic of functional motif with phenotypic trait variation [33]. Association studies identify genes and even functional motif within the genes that affect phenotypic characters [38]. But this approach is dependent on linkage disequilibrium (LD) mapping which rely on non-random occurrence of allele haplotype in the genome[39]. Low level of LD is essential for determining the effects of intragenic polymorphism on phenotypic changes. Association studies can identify sequence motifs affecting phenotypic trait expression in crops having low LD. Application of association studies may not suffice the distinction of causative from phenotypically neutral polymorphism in haplotype structure [38]. Functional markers developed through the involvement of association studies are termed as indirect functional markers (IFM) as only indirect (statistical) evidence of sequence motif function can be provided [33]. However, the direct proof of sequence motif function can be achieved after comparing the isogenic genotypes which differ in single sequence motif. These isogenic genotypes can be generated through the approach of TILLING and homologous recombinations [33]. The development of FMs for selected traits has been observed successfully in few crops. Iyer and McCouch [40] cloned gene xa-5 in rice which made it possible to develop functional markers for Xa5-mediated resistance to bacterial blight disease [41]. Several candidate genes for FM development which have potential for controlling agronomic traits have been cloned in different plant crops - Dwarf 8 in Maize [38] and OsARD2 in Rice [42].

\section{GENOTYPING-BY-SEQUENCING (GBS)}

The traditional DNA sequencing technologies could not meet the demand for indebt sequence information required in complex genomic research. With the advent of next generation sequencing technology (NGS), the knowledge gap is 
filled and the technology has become an inevitable everyday research tool in complicated genome studies [43]. Before the NGS came into being, Sanger or dideoxy sequencing was the most widely used DNA sequencing technique. But the Sanger sequencing is relatively expensive, laborious and time consuming apart from its inherent limitation of requiring in vivo amplification of DNA fragments to be sequenced. The limitations are overcome with the introduction of 454 technology in the market which was the first NGS technology which relied on the method of in vitro DNA amplification known as emulsion PCR [44]. 454 platform marketed by Roche Applied Science has the capability of generating $80-120 \mathrm{Mb}$ of sequence in 200-300 bp reads in 4 hour runs and is one of the most popularly used sequencing technologies in genome research. Recent advancements in NSG technologies make it possible the use of SNPs for genetic analysis to a new level. Genotyping-by-sequencing (GBS) first introduced by Elshire et al. [45] is a novel application of NSG protocols for discovering and genotyping SNPs in crop genome and populations. This is highly multiplexed system for constructing reduced representation libraries for the Illumina NGS platform generating good numbers of SNPs for employing in genetic analysis and genotyping [46]. GBS is a cost effective and efficient technique for genomics assisted breeding in varied crops like Cotton, Brassica, Sorghum and Miscanthus [43]. Using ion PGM systems, two GBS strategies have been developed [47]. The first approach is ideal for discovering new markers for MAS programs and no specific SNPs are identified with digestion by restriction enzymes. Genome complexity is reduced with DNA restriction digestion using one or two selected restriction enzymes before adapter ligation [48]. In the second approach, a set of SNPs is defined for particular genome region using PCR primer designed to amplify only the selected interest region of genome [47]. The use of sequencing restriction site associated genomic DNA (RAD) for discovery of high density SNP and genotyping is more complex and expensive as compared to GBS.

\section{CONCLUSION}

The varied molecular markers employed in plant research have been discussed along with their applications in genetic variability evaluation, genome fingerprintingand population genetic studies. Hybridization based DNA marker which is one of the pioneer markers for plant genetic diversity studies have been superseded by the development of more reliable and reproducible PCR based markers. However, either simple or more advanced molecular markers possess inherent strengths and weakness and none of them are perfect with shortcomings. Selection of the most appropriate marker will ultimately depend on the particular research approach adopted and degree of resolution and polymorphism required for the specific study. With rapid progress in molecular biology, more effective and superior markers may appear in near future which can significantly accelerate plant breeding research. The recent advancement of NGS technology which led to the development of GBS will also provide ultimate MAS tool for rapid enhancement in plant improvement and crop breeding.

\section{ACKNOWLEDGEMENT}

The authors are thankful to SERB (Science \& Engineering Research Board), New Delhi, India for the financial support. Authors also acknowledge the immense help received from the scholars whose articles are cited and included in references of this manuscript. The authors are also grateful to authors/ editors/ publishers of all the articles, journals and books from where the literature for this article has been reviewed and discussed.

\section{Conflict of Interest}

The authors declare that there is no conflict of interest regarding the publication of the paper.

\section{RERERENCES}

1. Hamrick JL. Isozyme and the Analysis of Genetic Structure in Plant Populations. In: Soltis DE, Soltis PS. Isozymes in Plant Biology, Dioscorides Press, Oregon, Portland. 1989; 87-105.

2. Nongdam P, Nirmala C. Genetic Variability in Four Species of Cymbidium Based on Isozyme Markers. Physiology Molecular Biology of Plants 2007; 13(1):65-68.

3. Avise JC. Molecular Markers, Natural History and Evolution. Sinauer Publication, USA 2004.

4. Horst L, Wenzel G. Molecular Marker Systems in Plant Breeding and Crop Improvement. Springer Verlag, Germany 2005; 74-76.

5. Potter RH, Jones MGK. Molecular Analysis of Genetic Stability. In: Dodds JH. In Vitro Methods for Conservation of Plant Genetic Resources, Chapman and Hall, London 1991; 71-91.

6. Southern EM. Detection of Specific Sequences among DNA Fragments Separated by Gel Electrophoresis. Journal of Molecular Biology 1975; 98: 503-517.

7. Coutinho JP, Carvalho A, Martin A, Ribeiro T, Morais-Cecílio L, Lima-Brito J. Oak Ribosomal DNA: Characterization by FISH and Polymorphism Assessed by IGS PCR-RFLP. Plant Systematics and Evololution 2016; 302: 527-544.

8. Nerkar G, Farsangi F, Devarumath R.Organellar Genome Diversity in Saccharum and Erianthus spp. Revealed by PCR RFLP. Molecular Plant Breeding2015; 6: 1-11.

9. Islam S, Mir JI,Kudesia R.Evaluation of Genetic Diversity in Vigna radiata (L.) using Protein Profiling and Molecular Marker (RFLP).International Journal of Plant Breeding and Genetics2015; 9: 238-246.

10. Mullis KB. The Unusual Origin of the Polymerase Chain Reaction. Scientific American1990; 262:56-61.

11. Lynch M, Walsh B. Genetics and Analysis of Quantitative Traits. Sinauer Associates, Sunderland, MA 1998. 
12. Vos P, Hogers R, Bleeker M, Reijans M, van de Lee T, Hornes M, Frijters A, Pot J, Peleman J, Kuiper M,Zabeau M. AFLP: A New Technique for DNA Fingerprinting.Nucleic Acids Research 1995; 23: 4407-4414.

13. Zietkiewicz E, Rafalski A, Labuda D. Genome Fingerprinting by Simple Sequence Repeat (SSR)-Anchored Polymerase Chain Reaction Amplification.Genomics 1994; 20: 176-183.

14. Nilkanta H, Amom T, Tikendra L, RahamanH, Nongdam P. ISSR Marker based Population Genetic Study of Melocanna baccifera (Roxb.) Kurz: A Commercially ImportantBamboo of Manipur, North-East India. Scientifica 2017; Article ID 3757238.

15. Semagn K, Bjornstad A, Ndjiondjop MN. An Overview of Molecular Marker Methods for Plants. African Journal of Biotechnology 2006; 5: 2540-2568.

16. Vignal A, Milan D, SanCristobal M, Eggen A. A Review on SNP and Other Types of Molecular Markers and Their Use in Animal Genetics.Genetics Selection Evolution2002; 34: 275-305.

17. Sobrino B, Brion M, Carracedo A. SNPs in Forensic Genetics: A Review on SNP Typing Methodologies.Forensic Science International2005; 154: 181-194.

18. Wallace RB, Shaffer J, Murphy RF, Bonner J, Hirose T, Itakura K. Hybridization of Synthetic Oligodeoxyribonucleotides to Phi 174 DNA: The Effect of Single Base Pair Mismatch. Nucleic Acids Research 1979; 6: 3543-3557.

19. Alcala J, Giovannoni JJ, Pike LM, Reddy AS. Application of Genetic Bit Analysis (GBA) for Allelic Selection in Plant Breeding. Molecular Breeding 1997; 3: 495-502.

20. Jaccoud D, Peng K, Feinstein D, Kilian A. Diversity Arrays: A Solid State Technology for Sequence Information Independent Genotyping. Nucleic Acids Research2001; 29: e25.

21. Collard BCY, Mackill DJ. Conserved DNA-derived Polymorphism (CDDP): A Simple and Novel Method for Generating DNA Markers in Plants.Plant Molecular Biology Reporter 2009; 27: 558-562.

22. Poczai P, Varga I, Bell NE,Hyvönen J. Genetic Diversity Assessment of Bittersweet (Solanumdulcamara, Solanaceae) Germplasm Using Conserved DNA Derived Polymorphism and Intron-Targeting Markers. Annals of Applied Biology 2011;159: 141-153.

23. Gorji AM, Poczai P, Polgar Z,Taller J. Efficiency of Arbitrarily Amplified Dominant Markers (SCoT, ISSR and RAPD) for Diagnostic Fingerprinting in Tetraploid Potato. American Journal of Potato Research2011; 88: 226-237.

24. Li G, Quiros CF. Sequence-Related Amplified Polymorphism (SRAP), a New Marker System based on a Simple PCR Reaction: Its Application to Mapping and Gene Tagging in Brassica. Theoretical and Applied Genetics2001; 103: 455-461.

25. Lin X, Kaul S, Rounsley S, Shea TP, Benito MI, Town CD, Fujii CY, Mason T, Bowman CL, Barnstead M, Feldblyum TV, Buell CR, Ketchum KA, Lee J, Ronning CM, Koo HL, Moffat KS, Cronin LA, Shen M, Pai G, Aken SV, Umayam L, Tallon JL, Gill JE, Adams MD, Carrera AJ, Creasy TH, Goodman HM, Somerville CR, Copenhaver GP, Preuss D, Nierman WC, White O, Eisen JA, Salzberg SL, Fraser CM, Venter JC. Sequencing and Analysis of Chromosome 2 of the plant Arabidopsis thaliana. Nature 1999; 402: 761-768.

26. Uzun B, Cagirgan MI. Identification of Molecular Markers Linked to Determinate Growth Habit in Sesame. Euphytica 2009; 166: 379-384.

27. Kalendar R, Flavell AJ, Ellis TH, Sjakste T, Moisy C, Schulman AH. Analysis of Plant Diversity with Retrotransposon-based Molecular Markers.Heredity2011; 106: 520-530.

28. Kalendar R, Antonius K, Smykal P, Schulman AH. iPBS: A Universal Method for DNA Fingerprinting and Retrotransposon Iso-
lation.Theoretical and Applied Genetics 2010; 121: 1419-1430.

29. Kelly NJ, Palmer MT, Morrow CD. Selection of Retroviral Reverse Transcription Primer is Coordinated with tRNA Biogenesis. Journal of Virology2003; 77: 8695-8701.

30. Monden Y, Fujii N, Yamaguchi K, Ikeo K, Nakazawa Y, Waki T, Hirashima K, Uchimura Y, Tahara M. Efficient Screening of the Long Terminal Repeat(LTR) Retrotransposons that Show High Insertion Polymorphism via High-Throughput Sequencing of the Primer Binding Site. Genome 2014; 57: 1-8.

31. Baránek M, Meszáros M, Sochorová J, Cechová J,Raddová J. Utility of Retrotransposon-Derived Marker Systems for Differentiation of Presumed Clones of the Apricot CultivarrVelkopavlovická.ScientiaHorticulturae2012; 143: 1-6.

32. Baloch FS, Derya M, Andeden EE, Alsaleh A, Comertpay G, Kilian B, Ozkan H. Inter Primer Binding Site Retrotransposon and Inter Simple Sequence Repeat Diversity among Wild Lens Species. Biochemical Systematics and Ecology2015;58: 162168.

33. Andersen JR, Lübberstedt T. Functional Markers in Plant.Trends in Plant Science2003; 8: 554-560.

34. Frisch M, Bohn M, Melchinger AA. Minimum Sample Size and Optimal Positioning of Flanking Markers in Marker-Assisted Backcrossing for Transfer of a Target Gene.Crop Science1999; 39: 967-975.

35. Bagge M, Lübberstedt T. Functional Markers in Wheat - Technical and Economic Aspects. Molecular Breeding 2008; 22: 319328.

36. Ingvardsen C, Schejbel B, Lübberstedt T. Functional Markers in Resistance Breeding. In: Lüttge U, Beyschlag W, Murata J. Progress in Botany. Springer-Verlag, Berlin. 2008; 61-87.

37. Lau WCP, Rafii MY, Ismail MR, Puteh A, Latif MA, Ramli A. Review of Functional Markers for Improving Cooking, Eating, and the Nutritional Qualities of Rice.Frontiers in Plant Science2015; 6(832).

38. Thornsberry JM,Goodman MM, Doebley J, Kresovich S, Nielsen D,Buckler ES. Dwarf8 Polymorphisms Associate with Variation in Flowering Time. Nature Genetics 2001; 28: 286-289.

39. Borevitz JO, Nordborg M. The Impact of Genomics on the Study of Natural Variation in Arabidopsis.Plant Physiology2003; 132: 718-725.

40. Iyer AS, McCouch SR. The Rice Bacterial Blight Resistance Gene XA5 Encodes a Novel Form of Disease Resistance.Molecular Plant- Microbe Interaction 2004; 17: 1348-1354.

41. Iyer-Pascuzzi AS, McCouch SR. Recessive Resistance Genes and the Oryza sativa-Xanthomonasoryzaepv. Oryzaepathosystem.Molecular Plant- Microbe Interaction2007; 7: 731-739.

42. Anuradha K, Agarwal S, Rao YV, Rao KV, Viraktamath BC, Sarla N. Mapping QTLs and Candidate Genes for Iron and Zinc Concentrations in Unpolished Rice of Madhukar $\times$ SwarnaRILs. Gene2002; 508: 233-240.

43. Kim C, Guo H, Kong W, Chandnani R, Shuang LS, Paterson AH. Application of Genotyping by Sequencing Technology to a Variety of Crop Breeding Programs.Plant Science2016; 242: 14-22.

44. Morozova O, Marra MA. Applications of Next-Generation Sequencing Technologies in Functional Genomics.Genomics2008; 92: 255-264.

45. Elshire RJ, Glaubitz JC, Sun Q, Poland JA, Kawamoto K, Buckler ES, Mitchell SE. A RobustSimple Genotyping-by-Sequencing (GBS) Approach for High Diversity Species. PloS One 2011; 6(5), Article ID e19379.

46. Beissinger TM, Hirsch CN, Sekhon RS, Foerster JM, Johnson JM, Muttoni G, Vaillancourt B, Buell CR, Kaeppler SM, de Leon N.Marker Density and Read Depth for Genotyping Populations 
using Genotyping-By-Sequencing.Genetics2013;193: 10731081.

47. Poland JA, Brown PJ, Sorrells ME, Jannink JL. Development of High-Density Genetic Maps for Barley and Wheat using a Novel Two-Enzyme Genotyping-By-Sequencing Approach.PLoS One 2012; 7(2) Article ID e32253.
48. He J, Zhao X, Laroche A, Lu ZX, Liu H, Li Z. GenotypingBy-Sequencing (GBS), an Ultimate Marker-Assisted Selection (MAS) tool to Accelerate Plant Breeding. Frontiers in Plant Science2014; 5: 1-8. 